\title{
Unraveling the dynamics of wetland degradation in megacity Dhaka
}

\author{
Meherun Mukti ${ }^{1}$, Md. Sarwar Hossain ${ }^{2}$, Bhoktear Khan ${ }^{3}$, M Giashuddin Miah ${ }^{1}$, and Hasan \\ Abdullah ${ }^{4}$ \\ ${ }^{1}$ Bangabandhu Sheikh Mujibur Rahman Agricultural University \\ ${ }^{2}$ University of Bern \\ ${ }^{3}$ University of Delaware \\ ${ }^{4}$ BSMRAU
}

June 4, 2020

\begin{abstract}
Despite recognizing the role of wetlands in providing ecosystem services to human wellbeing, around $70 \%$ of the wetland ecosystems are destroyed globally since the 1990s. In particular, wetland ecosystems are destroyed in response to faster economic, urban, and population growth in the world megacities and developing countries. In contrast, wetlands ecosystems have received less attention in research and policy. Therefore, we made a first attempt to unravel the Spatio-temporal dynamics of wetlands in the Dhaka city of Bangladesh, which is one of the fastest-growing megacities in the world. The results show that a total of $\sim 1,600$ ha ( 50\% of the total wetlands) wetlands have been lost in Dhaka from 1990 to 2015 . In contrast, the land-use types that increased the most were built-up, which increased by $\sim 9,250$ ha (378\%) since 1990. These changes are mainly due to rapid urbanization and industrialization. It has been observed that Land Surface Temperature (LST) has increased $15 \mathrm{oC}$ within 30 years in those lands which converted from wetlands to landfill. In addition to the increase in LST, drainage congestion, depletion of groundwater are increasing in response to wetlands degradation. The restoration of wetlands into the initial state of the 1990s would be highly challenging. However, efforts should be made to restore wetlands which offers potential as a nature-based solution to cope with climate change. These findings can be used as a reference in the formulation and implementation of sustainable wetlands management policies.
\end{abstract}

\section{Hosted file}

final_wetland_03June 2020.doc available at https://authorea.com/users/329861/articles/456733unraveling-the-dynamics-of-wetland-degradation-in-megacity-dhaka

\section{Hosted file}

table_03June 2020.doc available at https://authorea.com/users/329861/articles/456733unraveling-the-dynamics-of-wetland-degradation-in-megacity-dhaka 


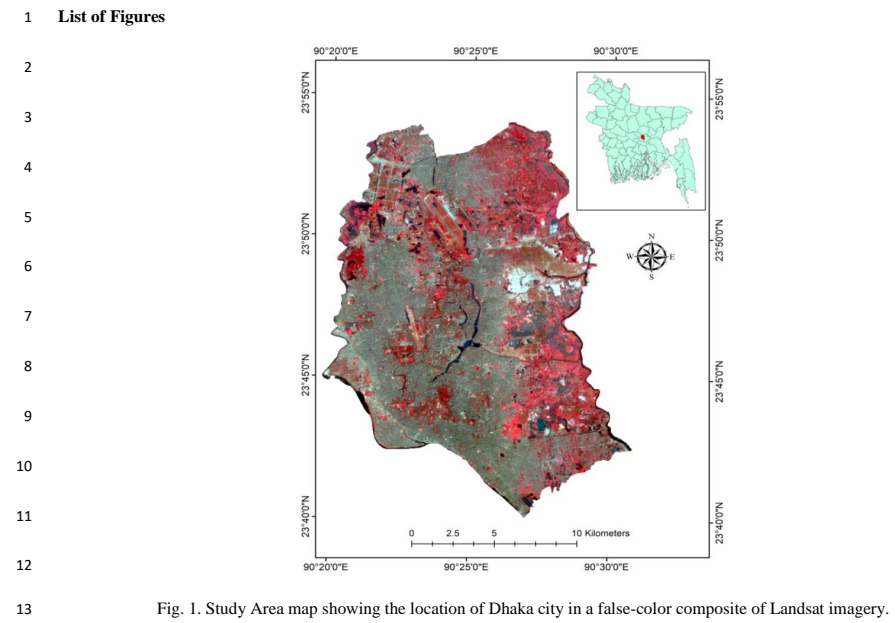

